\title{
Collaborative Governance Response to COVID-19 Pandemic in Indonesia
}

\author{
Bagus Tjahjono* \\ Faculty of Medicine \\ Universitas Jenderal Ahmad Yani \\ Cimahi, Indonesia \\ *bagustjahjono22@gmail.com
}

\author{
Agus Suryono, Riyanto, Fadillah Amin \\ Faculty of Administration Science \\ Universitas Brawijaya \\ Malang, Indonesia
}

\begin{abstract}
The COVID-19 pandemic has hit and is attacking Indonesia. This pandemic is very difficult to eradicate. The Indonesian government has formed a task force for handling the COVID-19 pandemic. The duties and functions of this task force are to coordinate and lead the six main components in the collaborative mechanism for handling the COVID-19 pandemic. The purpose of the research is to explain the application of collaborative governance in handling COVID-19 pandemic in Indonesia. This study used a descriptive analytical method using data derived from the data on handling this pandemic. The results obtained indicate that Indonesia is implementing a collaborative governance approach in the effort to tackle the COVID-19 pandemic. The implication of this research is the need to increase collaboration at the operational level. Research can be further developed to find a collaborative governance model in dealing with pandemics in Indonesia.
\end{abstract}

Keywords-collaborative governance, COVID-19 pandemic, task force

\section{INTRODUCTION}

Currently, the COVID-19 pandemic has hit and is attacking the world, around 219 countries and territories in the world, including Indonesia, have become victims of this disease. Called a global disaster, the COVID-19 pandemic is very difficult to eradicate, causing very high mortality and detrimental to various aspects of life. The majority of countries in the world have lost and are fighting their best to overcome this pandemic. Various methods and ways are used by these countries in an effort to respond to the COVID-19 pandemic, one of which is through a collaborative governance approach.

Studies on the methods or ways of a country dealing with the COVID-19 pandemic have been widely published. Generally, countries handle the COVID-19 pandemic by forming a task force but rarely do specifically use a collaborative governance approach. There are no studies in Indonesia that specifically discuss a collaborative governance approach in handling the COVID-19 pandemic nationally.

Overcoming the COVID-19 pandemic requires extraordinary efforts and involves all levels of society because pandemics are our common concern. In the emergency situation of the COVID-19 pandemic, the government cannot work alone, but requires a collaborative governance mechanism [1]. From the government side, it must comprehensively mobilize and coordinate all potentials of central and local government institutions. From the community side, the active involvement of all levels of society is to mobilize their potential and resources to help the government cope with the COVD-19 pandemic. In Indonesia, there is no research related to a collaborative governance approach in overcoming the COVID-19 pandemic nationally. The purpose of this study is to analyze the collaborative governance approach carried out in Indonesia to tackle the COVID-19 pandemic.

\section{RELATED WORKS / LITERATURE REVIEW}

A. Review and Analysis of Current Responses to COVID-19 in Indonesia: Period of January to March 2020, by

Djalante, et al. [2]

The first reference is a review article published in the Journal Progress in Disaster Science 6 (2020) 100091. The study aims to provide detailed report and analyses of the responses to COVID-19 in Indonesia. The study highlights responses taken by the government, non-government organizations and the community. The results outline gaps and limitations in the responses and presents recommendations toward rapid, effective, and comprehensive responses. This study does not analyze specifically about collaborative governance [2].

\section{B. Indonesia's Crises Response to COVID-19 Pandemic:}

from Various Level of Government and Network Actions to Policy, by Yulianti, et al. [3]

The second reference is a journal article published in the Journal of Public Administration, Finance and Law (2020) Issue 17. The study is qualitative research focused on the actual textual documents as the objects of analytical content from internet and articles. The objectives of the research are: notifying Indonesia government's action towards COVID-19 pandemic; identifying government's policies and analyzing 
Indonesia's crises response management to control COVID-19 pandemic. The result is that Indonesia is still slow to response the pandemic. This study does not analyze specifically about collaborative governance [3].

\section{Collaborative Governance as Handling Efforts of Pandemic COVID-19 in Surabaya City by Megawati et al.} [1]

The third reference is a journal article published in the Advances in Social Science, Education and Humanities Research, Vol 473. The study provides a comprehensive scheme of the effectiveness of the collaborative governance process in the form of dynamics, collaborative actions, and the expected impacts in the efforts to deal with the spread of COVID-19 carried out by the task force of Surabaya City. This study does not explore the collaborative governance approach in the national level [1].

\section{Toward a Collaborative Model of Pandemic Preparedness and Response: Taiwan's Changing Approach to \\ Pandemics by Schwartz and Yen [4].}

The fourth reference is a review article published in the Journal of Microbiology, Immunology, and Infection, 50, 125132. This study analyzes the results of various studies found in the collaborative governance literature that state-community cooperation contributes to effective implementation from a pandemic preparedness and response perspective in Taiwan. The result is that Taiwan's collaborative approach facilitates trust-building and understanding of local conditions and vulnerabilities while enhancing capacities and more effectively allocating resources for pandemic prevention and control [4].

\section{E. The Power of Collaborating Governance: The Case of South Korea Responding to COVID-19 Pandemic by Choi [5]}

The fourth reference is a journal article published in the World Medical and Health Policy. Dec; 12(4): 430-442. This study explores the synergy produced by the entire governance system participated in by various actors, including both public and private ones, namely the collaborative governance, as an important factor of its more successful control of the epidemic compared with other countries. The result is that the South Korean public health system's battle against COVID-19 is a great example of collaborative governance. A number of policy decisions made and conducted in South Korea have been identified by researchers and the media as critical factors in the country's successful management of the situation. The implementation of these policies requires the entire governance system needs to be able to work smoothly and effectively, and in order to do so, a high level of coordination and cooperation among various actors in both public and private sectors is important [5].

\section{F. Governance of the Covid-19 Response: A Call for More Inclusive and Transparent Decision-Making by Rajan et al. [6]}

The fifth reference is a journal article published in the BMJ Global Health, 5:e02655. This study analyzes the decisionmaking process and how policy makers and politicians consult with experts during the COVID-19 pandemic. This study conducted a rapid analysis of 24 countries' COVID-19 task force compositions. The result is that governments must recognize the multidimensional effects and needs of society during Covid-19 crisis and consult more broadly and across disciplines, within health and beyond health, based on a true multisector paradigm. More transparency is needed regarding who decision-making bodies are listening to as a basis for their decisions. This paper analyzes the composition of the task force, but there is no aspect of collaborative governance [6].

\section{G. Collective Action During the COVID-19 Pandemic: The Case of Germany's Fragmented Authority by Hattke and Martin [7]}

The sixth reference is a journal article published in the ADMINISTRATIVE THEORY \& PRAXIS, VOL. 42, NO. 4, 614-632. This study explores how a system based on fragmented authority achieves collective action that amounts to an effective response to a crisis. The case of Germany is critical and politically important in point to counter the calls for more centralized and hierarchical approaches to the COVID-19 pandemic. The result is that how coordination, cooperation, and collaboration can help enable collective action. The insights can help policymakers and administrators understand better how a decentralized, resilient public health system can be designed and what challenges this may involve [7]

\section{Methodology}

This study uses a descriptive-analytical approach by analyzing the handling of the COVID-19 pandemic carried out by the Indonesian government. Primary data and information were obtained from observing and attending meetings related to the handling of the COVID-19 pandemic. Analyzing secondary data in the form of government regulations, presidential regulations, ministerial regulations, also policies from the COVID-19 task force, news from the media, seminars, and workshops related to managing to the COVID19 pandemic.

\section{RESULTS AND DISCUSSION}

Indonesia first confirmed the COVID-19 case on March 2, 2020. And soon the government declared COVID-19 a national pandemic. As a legal basis, Presidential Decree No.7 of 2020 concerning the Task Force for Accelerating of Handling COVID-19 was issued. Then issued Presidential Decree No. 12 of 2020 concerning the Determination of Non-Natural Disaster for the Spread of Corona Virus Disease 2019 (COVID-19) as a National Disaster. This Presidential Decree is the basis and 
guideline for the implementation of handling the COVID-19 pandemic in Indonesia [2].

Government policies for handling the COVID-19 pandemic, namely: implementing health protocols (wearing masks, maintaining distance, washing hands), conducting tests, tracing, treatment and restricting community movement.

The implementation of this policy is not easy because it is related to the compliance and discipline of the community towards changes in their behavior. There is a new strategy of governing called "collaborative governance" that brings multiple stakeholders together in common forums with public agencies to engage in consensus-oriented decision making [8]. So there is a need for a collaboration mechanism from all elements of government and society so that policies and programs for handling the COVID-19 pandemic can be carried out properly.

The collaborative governance approach in handling the COVID-19 pandemic is a collaboration of six main elements, namely: central and local government; civil society and volunteers, private sectors and media, medical facilities and hospitals, and the military (Figure 1).

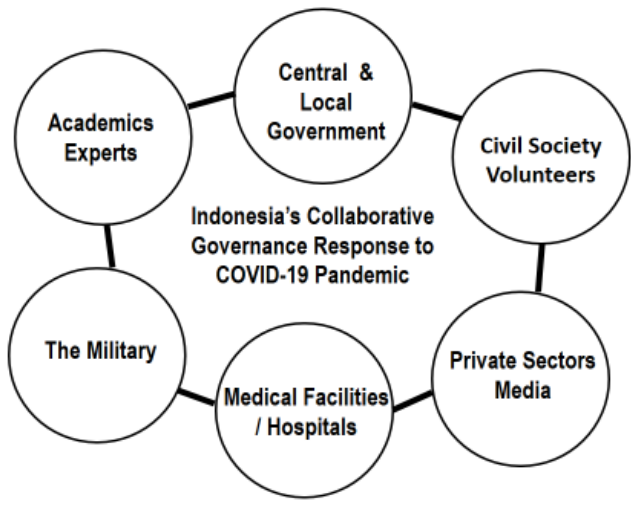

Fig. 1. Actors participating in collaborative governance of indonesia in response to COVID-19.

\section{A. Central and Local Government}

Collaboration between the central government and local governments is at the forefront of the successful handling of the COVID-19 pandemic. All activities to deal with the COVID-19 pandemic are under the coordination and command of the COVID-19 pandemic task force. The policies of the central government are coordinated and implemented by local governments, from the provincial, district, city, sub-district, to village levels. The regional head is responsible for implementing health protocol policies and restricting community movement. The results of the response to COVID19 in the regions are reported to the central government for evaluation. Areas with cases of COVID-19 infection receive attention and support from the central government. Central government assistance includes: masks, COVID-19 test kits, PCR test kits, personal protective equipment, reagents, medical equipment for hospitals, ambulances, vaccines and other supporting equipment. However, central and local collaboration still has problems at the operational level, namely miscoordination of case reporting, laboratory operations, limited PCR equipment, and deployment of personnel and volunteers [9].

\section{B. Civil Society and Volunteers}

There is an important group of civil society organization whose social function becomes very evident in times of great public commotion. There have been various examples of the spontaneous mobilization of civil society for minimizing the damage from COVID-19, and this response could be expanded with the support and coordination of government [10]. Collaboration between the government and civil society has a very important role because the community is both the object and the subject of the successful response to the COVID-19 pandemic. Public awareness and discipline in practicing health protocols and social restrictions are determining factors that contribute to the success of overcoming this pandemic. The community is often blamed if the number of COVID-19 infections in their area is high. The public is required to comply with government policies, although the government often lack of attention and support to the community. The community also mobilizes the COVID-19 volunteer movement which assists local governments in campaigning for health protocols, distributing masks, volunteering in tracing, and implementing social restrictions in their areas. There is a need to take a collaborative approach in Covid-19 management, including greater involvement of the civil society organizations to support the efforts of the government to manage the pandemic. The civil society organizations played a pivotal role by monitoring the situation closely, assisting the government, and reaching the most vulnerable social groups [11].

\section{Private Sectors and Media}

Collaboration with the private sector leads to effective responses to crises because private sector can provide more resources and information and possesses stronger capacity to produce better results [12]. It holds true, that collaboration between Indonesia government and the private sector and business in helping central and local governments to cope with the COVID-19 pandemic is very important. Contributions from the private sector vary such as ambulance assistance, covid-19 testing kits, PCR testing kits, masks, personal protective equipment, medicines, and campaigns on health protocols. The role of media, both electronic and social media, is important in providing correct information to the public. The media ward off hoax news and also regularly helps disseminate information related to the development of handling COVID-19 delivered by the spokesperson for the task force handling COVID-19. Private sector involvement in humanitarian and health crises is not a new phenomenon. The scale and reach of the Covid-19 pandemics have created a global supply chain crisis, with many countries facing shortages in medical equipment such as surgical masks and ventilators. In this context, the private sector is stepping up efforts to manage the pandemic. The private sector input can help meet the short-term needs of 
frontline health workers. It also demonstrates how all companies, not just those in the healthcare industry, are doing their part to address COVID-19 problems [13].

\section{Medical Facilities and Hospitals}

Collaboration between the government and hospitals and health facilities has been proven to provide easy access and increase capabilities in handling COVID-19 patients [14]. In Indonesia, collaboration between the government and medical facilities, hospitals and other health facilities is very important. There are 3 (three) types of hospitals that are prepared to treat patients of COVID-19, namely: a hospital to treat patients with symptoms, a hospital that functions to treat patients without symptoms, and a field hospital that is prepared as a support. The public health center functions to carry out testing and tracing to the community. A laboratory car was formed which aims to reach extensive testing in remote locations. The hospital workload is very heavy because the number of patients to be treated is very high. Even doctors, nurses, health workers have also become victims and have died from COVID-19.

\section{E. Academics}

Collaboration with academics and experts in tackling the COVID-19 pandemic was manifested by the inclusion of experts in the organizational structure of the task force handling COVID-19. Various disciplines of health, medical, psychological, economic, social, legal expertise and so on provide advice for policy implementation. Experts are directly involved in field operations related to health protocols and restricting the movement of people. Provide accurate and scientific information about the COVID-19 pandemic so that people feel safe and calm. Related to the importance of the role of experts in collaboration in handling COVID-19 pandemic, Portes said that the group's authority is not limited to medical science; much of the group's recent advice relates to public acceptance and the sustainability of intervention, such as limiting public gathering. So, even as behavioral scientist' it seems odd not to get input on this issue from sociologist and public opinion experts, as well as virologists and statisticians [15].

\section{F. The Military}

Collaboration between the civilian and the military is an interesting study in the public administration arena. Military involvement in emergency crisis conditions is very much needed and it crosses the boundaries of collaborative governance's norm. This conditions fits the definition of collaborative governance regime as the processes and structures of public policy decision making and management that engage people constructively across the boundaries of public agencies, levels of government, and/or the public, private and civic spheres in order to carry out a public purpose that could not otherwise be accomplished [16]. From experience in America that partnership with government, military, and local health care organizations was essential for logistical and medical support [12]. In Indonesia collaboration with the military in dealing with natural disasters has been going on for a long time and is going well. So that for nonnatural disasters such as the COVID-19 pandemic, Indonesia Armed Forces / TNI are directly involved. The TNI is included in the organizational structure of the task force for handling the COVID-19 pandemic. The strength of the TNI is that it has a network of territorial units in all corners of the country with the distribution of personnel down to the village level. The TNI's ability to move quickly by deploying equipment, logistics and personnel to contribute to handling the COVID-19 pandemic. TNI officers are at the forefront of national and local COVID19 mitigation efforts and health protocols. The TNI established four integrated joint task commands, COVID-19 emergency hospitals, and quarantine facilities. TNI also assists various COVID-19 related tasks, such as maritime and airborne evacuations, quarantine patrol, distributing medical supplies and vaccines.

\section{CONCLUSION AND Future SCOPE}

Indonesia applies a collaborative government approach to tackle COVID-19 pandemic. The task force for handling the COVID-19 acts as a coordinator and leader in this collaborative mechanism. The collaborative governance approach must be improved at the operational level. For further research, there is an opportunity to find a collaborative governance model that is considered more appropriate to overcome the COVID-19 pandemic in Indonesia.

\section{REFERENCES}

[1] S. Megawati, F. Niswah, and T.A. Oktariyanda, "Collaboration Governance as Handling Efforts of Pandemic Covid-19 in Surabaya City," Advances in Social Science, Education and Humanities Research, vol. 473, pp. 312-316, 2020 .

[2] R. Djalante, J. Lassa, D. Setiamarga, A. Sudjatma, M. Indrawan, B. Haryanto, and H. Warsilah, "Review and analysis of current responses to COVID-19 in Indonesia: Period of January to March 2020," Progress in Disaster Science 6, 2020

[3] D. Yulianti, B. Sujadmiko and I.F. Meutia, "Indonesia' Crisis Response to Covid-19 Pandemic: from Various Level of Government and Network Actions to Policy," Journal of Public Administration, Finance and Law, Issue 17, 2020.

[4] J. Schwartz and M.Y. Yen, "Toward a Collaborative model of pandemic preparedness and response: Taiwan's changing approach to pandemics," Journal of Microbiology, Immunology and Infection, vol. 50, pp. 125$132,2017$.

[5] Y.J. Choi, "The Power of Collaboration Governance: The Case of South Korea Responding to COVID-19 Pandemic," World Medical and Health Policy, vol. 12:4, 2020.

[6] D. Rajan, K. Koch, K. Rohrer, C. Bajnoczki, A. Socha, M. Voss, and J. Koonin," "Governance of the Covid-19 response: a call for more inclusive and transparent decision-making," BMJ Global Health, 5:e002655, 2020

[7] F. Hattke, and H. Martin, "Collective action during the Covid-19 pandemic: The case of Germany's fragmented authority," ADMINISTRATIVE THEORY \& PRAXIS, vol. 42, no. 4, pp. 614-632, 2020

[8] C. Ansell, and A. Gash, "Collaborative Governance in Theory and Practice," Journal of Public Administration Research and Theory, November 2007. 
[9] N.S. Saputri, "Liku-Liku Peningkatan Kapasitas Pengetesan COVID-19 dengan Metode PCR (The twists and turns of increasing the testing capacity of Covid-19 using PCR method)," The SMERU Research Institute, Sen, 07/13/2020

[10] M.A. Alves, and M.M. Costa, "The collaboration between governments and civil society organizations in response to emergency situations," BRAZILIAN JOURNAL OF PUBLIC ADMINISTRATION, vol. 54(4), pp. 923-935, 2020.

[11] M. Gopal, "Importance of Civil Society Organization in Managing Covid-19 Pandemic," Outlook, April 28, 2021

[12] A.W. Baughman, et al, "Pandemic Care Through Collaboration: Lessons From a COVID-19 Field Hospital," The Journal of Post-Acute and Long-Term Care Medicine, vol. 21, pp. 1563-1567, 2020.
[13] C. Chen, "COVID-19: Private sector's Role in Times of Crises," RSIS COMMENTARY Global Health Security, No. 051-26 March 2020

[14] Y. Mao, "Combating COVID-19 Through Collaborative Governance: Lesson from East Asia," Chinese Public adminlistration Review, vol. 11 Issue 2, August 2020

[15] J. Portes, "Economic and epidemiology in time of Covid-19," Campaign for Social Science, 15 May 2020

[16] K. Emerson, T. Nabatchi, Stephen Balogh, "An Integrative Framework for Collaborative Governance," Journal of Public Administration Research and Theory, May 2011. 